the vegetation zones and varied habitats. The reserves may be in no way comparable to East African parks in terms of animal numbers and diversity of species; nonetheless, given time and proper management, they will recover to their carrying capacity. The book is therefore equally for the politician as well as for the administrator.

There is a useful list of books for further reading which again shows how little is published about the large mammals of this region.

E. O. A. ASIBEY

\title{
The Gardeners of Eden, by A. D. Graham. Allen \& Unwin,
} £4.00.

No professional biologist or naturalist would deny that we need to extract some of the sentiment and emotion from the conservation movement and inject some ecological commonsense into its practice.

In the course of ten rambling chapters, the author of this book attempts to outline man's attitude to wildlife in general and its conservation in particular. He begins with a brief historical outline of hunting and the concept of game preserving (or 'saving'), and from here leaps to the situation in East Africa where, with the aid of government reports and a great deal of conjecture, he describes what he considers to be the dichotomous impulse to kill on the one hand and to protect and preserve on the other.

To attack early wardens such as Pitman and Ritchie for their lack of ecological insight must surely be done with the benefit of 1973 hindsight. At the time when these men were attempting to build up game departments, and to stand between the pressures of land usage on the one hand and wildlife on the other, ecology was an academic discipline understood by only a handful of trained biologists. They worked with a natural history background and an energy and zeal that is often sadly lacking in our modern society.

Mr Graham then attempts to explain "why men preserve and ultimately save wild animals'. He does this largely by recourse to the fields of behaviour and psychology, concluding with the assertion that 'game saving is nothing more than the outcome of repressed aggression redirected on to animals by humans paralysed in their relations with their fellow men'.

At this point one is forced to ask what were the author's motives in writing this book at all. As a work of scholarship, the function of which is to explain the development of the conservation concept, one would hope it could be taken seriously. But as the bitter attacks on individuals accumulate, and the reader is presented with the sweeping generalisation that 'game preservation provides a refuge for human malcontents', one ceases to do so. Indeed one cannot help feeling that the psychoanalysis of the game-savers' motives tells us more about the apparently deeply embittered writers than about the game savers.

Nobody would surely dispute that the call of the wilderness often attracts individuals who want to escape and have decided that the peace offered by these regions is worth preserving. But to suggest that their motives can only be explained by recourse to the more sensational realms of Freudian psychology, oedipal complexes and phallic symbolism does little credit to the cause of tropical ecology or to the author's scientific reputation and motives. On the few occasions when he uses unquestionable scientific facts to support his thesis, they are treated with the same air of contemptuous ridicule. Although no student of Pleistocene biology would accept the theory of a Pleistocene overkill as proven beyond doubt, to dismiss the concept briefly as a myth suggests that the author is not familiar with the literature on the subject.

It is a pity that, in writing about such an important subject, the author should have allowed himself to fall into the snare of the very emotionalism 
that he set out to destroy, for in so doing we are left with a work that is of little consequence to either the student of wildlife biology or the psychologist.

MALCOLM COE

South's British Butterflies, by T. G. Howarth. Warne, $£ 10.50$. Colour Identification Guide to British Butterflies, by T. G. Howarth, Warne, f3.00.

Richard South's classic work on British butterflies first appeared in 1906, and has served as the standard work ever since. We are told that T. G. Howarth, a world authority on butterflies, in revising South's work, has retained the charm and character of the original, but one's initial impression is of something completely new. Gone is the compact, easily held 'Wayside \& Woodland' format, and in its place a splendid, but not-so-portable, textbook.

Part One comprises The Life Cycle of a Butterfly; Conšervation (a new and very relevant addition); and Collecting - the last embodying up-to-date information on techniques and apparatus. Part Two, the major section of the book, covers the species descriptions, and it is a joy to use. The nine families, from Hesperiidae (Skippers) to Danaidae (Monarchs) are arranged in ascending order of specialisation; within the families each species is presented under a standard series of headings making for easy reference. It is in this orderly presentation of detailed information that this section scores heavily over its predecessor. A particular query can be answered quickly, and the inclusion of the heading 'History' for each species adds information only previously available from specialised journals.

In addition to the 70 species now included in the British list, the author has added details of 'reputed British species' and also of those 'accidental imports' reported, and presented, to the British Museum.

The 24 colour plates of adult butterflies are skilfully painted by A. D. A. Russwurm, who also drew the 27 text figures. A further 24 plates of developmental stages by R. D. Davis, copied from the originals of F. W. Frohawk, are extremely fine.

It is with the colour plate section that the reviewer is not happy with this otherwise excellent book. First, the magnification $\times 1 \frac{1}{4}$ makes the specimens appear unreal, and this impression is enhanced by the method of depicting only half specimens of upper and undersides. Secondly, a better follow-on of the plates of adults and larvae would seem possible. The author's reason for illustrating half specimens is the need to include as much material as possible-might this not have been achieved by depicting them as complete insects at natural size?

Where relevant, subspecies are illustrated, but an omission is the interesting Western Inverness-shire race of the chequered skipper. A number of striking variations are figured, including unfortunately, in some instances, full details of their provenance-the county alone would have sufficed. Naturalists' trusts have difficulty in wardening some of their reserves, and to see a particular hill mentioned when referring to a figured butterfly variation must surely make their work more arduous.

The inclusion of provisional maps of the resident species, prepared by John Heath at the Biological Records Centre, Monks Wood, is a valuable addition which has been missing from most previous works. The book concludes with a Classified List of Species, an Identification Key, and a Further Information section.

In summary, the author must be congratulated upon producing an outstanding work.

The second book is essentially a lightweight version of the first, with the 